\title{
New Brunswick seeks better system for physician recruitment to rural areas
}

\author{
— Cite as: CMAJ 2018 December 17;190:E1491-2. doi: 10.1503/cmaj.109-5693
}

Posted on cmajnews.com on Nov. 29, 2018.

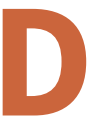
octors in New Brunswick are happy with the provincial government's new plan to do away with the unpopular billing-number system that controls where, and how many, physicians can practise in the province.

The government recently announced that it would "work with doctors on alternatives to billing numbers and on payment models that encourage collaboration, wellness, and the creation of community clinics."

Dr. Serge Melanson, president of the New Brunswick Medical Society, says doctors have been advocating for a change to the policy for some time. "We're really pleased to see that our government made a commitment to find an alternate and more modern way of recruiting and retaining physicians rather than the antiquated billing-number system," he says.

To practise medicine in New Brunswick, doctors must be assigned a medicare billing number by one of the two regional health authorities. The system was created in 1992 as a way of ensuring an equitable distribution of doctors across the province. A portion of billing numbers are assigned to different areas to encourage doctors to practise in rural and underserved areas. It is the only prov- ince to use this system, and Melanson says it has been too rigid.

"It has never proven to be effective for recruiting physicians to any area of the province, whether it be rural or urban," he says. "We hear pretty consistently from prospective candidates looking to set up in the province that they were really hesitant to consider New Brunswick specifically because of this restrictive billingnumber system."

Another issue is that, since each number represents a single doctor, physicians approaching retirement who decide to shift to part-time work retain their

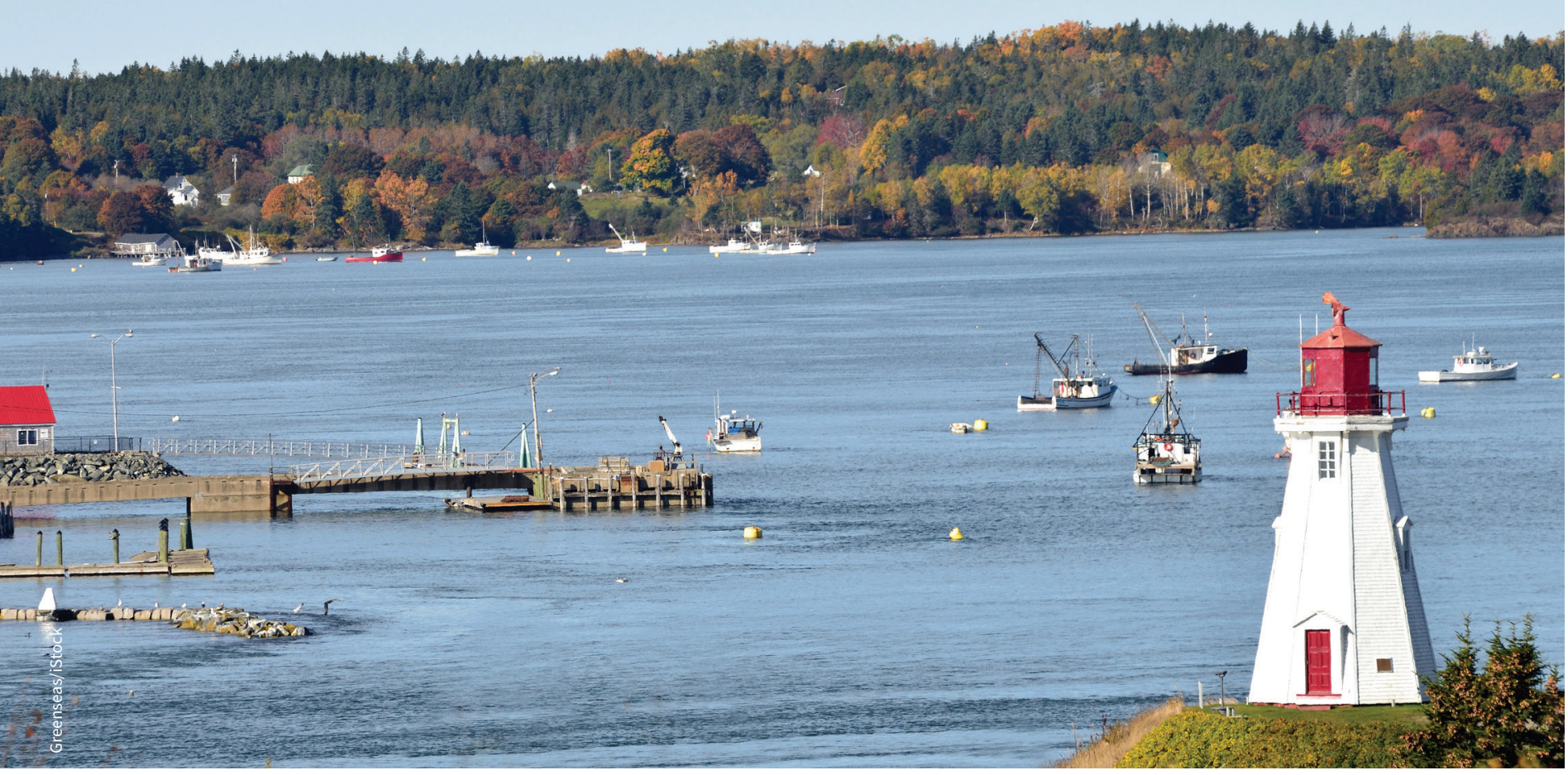

New Brunswick is struggling to attract doctors to rural areas. 
numbers and the province's department of health doesn't always generate new ones to fill the gap. The department of health did not respond to enquiries about what might replace the billing-number system, or how it would ensure there are enough doctors in rural areas.

Melanson wants the government to sit down with the New Brunswick Medical Society and the regional health authorities to decide what the new system should look like. "We need a better partnership with the health authorities; they have a better sense of the needs of any given community," he says.

Since recruitment and retention for underserved areas is a challenge everywhere, Melanson wants to look at what incentives, financial or otherwise, have worked in other parts of the country. Municipalities, for example, could play a larger role in a more holisitic approach to recruitment, because what attracts doctors to an area is not solely money or the practice environment. The medical society is also considering bringing in an external consultant to help with a more proactive recruiting drive.

"It's 2018 and we're still struggling to recruit in some areas," says Melanson. "We need to modernize the system."

Brian Owens, St. Stephen, NB 